\title{
Boundary negotiations: a paradox theoretical approach for efficient and flexible modular systems
}

Article

Accepted Version

Davies, P., Parry, G., Phillips, L. and Ng, I. C. L. (2021) Boundary negotiations: a paradox theoretical approach for efficient and flexible modular systems. International Journal of Operations \& Production Management. ISSN 0144-3577 doi: https://doi.org/10.1108/IJOPM-08-2020-0543 Available at https://centaur.reading.ac.uk/97496/

It is advisable to refer to the publisher's version if you intend to cite from the work. See Guidance on citing.

To link to this article DOI: http://dx.doi.org/10.1108/IJOPM-08-2020-0543

Publisher: Emerald

All outputs in CentAUR are protected by Intellectual Property Rights law, including copyright law. Copyright and IPR is retained by the creators or other copyright holders. Terms and conditions for use of this material are defined in the End User Agreement.

www.reading.ac.uk/centaur 
Central Archive at the University of Reading

Reading's research outputs online 


\title{
Boundary Negotiations: a paradox theoretical approach for efficient and flexible modular systems
}

\author{
Abstract \\ Purpose: The purpose of this paper is to explore the interplay between firm boundary decisions and \\ the management of both-and efficiency and flexibility and the implications this has for modular \\ design in the provision of advanced services. \\ Design/Methodology/Approach: A single case study in the defence industry employs semi- \\ structured interviews supplemented by secondary data. Data is analysed using thematic analysis. \\ Findings: The findings provide a process model of boundary negotiations for the design of efficient \\ and flexible modular systems consisting of three phases; boundary ambiguity, boundary defences and \\ boundary alignment. \\ Practical implications: The study provides a process framework for boundary negotiations to help \\ organisations navigate the management of both-and efficiency and flexibility in the provision of \\ advanced services.
}

Originality/Value: Drawing upon modularity, paradox and systems theory, this article provides novel theoretical insight into the relationship between firm boundary decisions and the management of bothand efficiency vs. flexibility in the provision of product upgrade services.

Keywords: servitization; modularity; paradox theory; advanced services; product upgrade services; firm boundary; boundary negotiation

Paper type: Research paper 


\section{Introduction}

Advanced services focus on the capabilities provided by a product's performance in use (Baines \& Lightfoot, 2014). To design advanced services, research suggests a modular design strategy (Davies, 2004; Rajala et al, 2019). Modularity is a method for managing complex products and services efficiently (Baldwin \& Clark, 2000) and refers to the degree to which a system's components can be separated and recombined with ease (Schilling, 2000). Modularity supports greater flexibility in design (MacCormack et al, 2001) and efficiency in production (Salvador et al, 2002) for the mass customisation of products and services (Baldwin \& Clark, 2000). Modularity is seen as a coping practice for the management of competing tensions of efficiency and flexibility, helping firms move away from either-or decisions towards both-and solutions for advanced services (Kohtamäki et al, 2020).

Creating flexibility in design and gaining economies of scale in production in the design means that once a modular product is in use, the opportunity for functional redesign is limited because the structural and functional elements of the modular architecture are frozen prior to production (Salvador, 2007; Henfridsson et al, 2014). Some servitization scholars adopting a systems lens question whether the scientific approach to modularity is appropriate for advanced services $(\mathrm{Ng} \&$ Briscoe, 2012; Davies et al, 2020) given service providers need to provide advance product upgrade services to match customer induced variety during the use of the product (Sousa \& da Silvieira, 2017). Recently, Davies et al. (2020) found that matching customer induced variety through product upgrade services results in a loss of modularity in the product's architecture.

Literature appears divided on whether modularity is a coping practice for managing both-and efficiency and flexibility in advances services, or if it is insufficient and emergent requirements will need to be accommodated postproduction with subsequent loss of modularity. To address calls for theoretical enrichment of servitization (Kowalkowski et al, 2017) and explore the management of both-and efficiency and flexibility in advanced services, this research integrates modularity, systems and paradox theory (Batista et al, 2017; Kohtamäki et al, 2020) to address the following research question: How do organisations manage the competing demands of efficiency and flexibility in the provision of advanced services?

The research question is addressed using an in-depth single case study of a manufacturer providing product upgrade services, defined as an advanced service that modifies product functionality to "match customized customer requirements arising throughout product usage" (Sousa $\&$ da Silvieira, 2017, pp. 454). The paper has three main findings. First, reflecting on the firm boundary as a coping mechanism for the management of organisational paradox, this article finds that the function of the boundaries interface between the provider and the customer has implications for the management of both-and efficiency and flexibility in the provision of advanced services. Second, a process model is provided to describe modularity in the delivery of advanced services, the tensions 
between efficiency and flexibility, and how boundary negotiations between provider and customer serve as mechanisms for paradox resolution. Finally, this study finds that the design of a modular product cannot be separated from the service it is attached to. To successfully manage both-and efficiency and flexibility a holistic view of the products and service components within the service system needs to be taken, with strategic alignment between components of the system the objective of service design.

Findings contribute to modularity and servitization literature by expanding understanding of the interplay between firm boundaries and management of efficiency and flexibility in the context of modular product-centric advanced services. Previous modularity studies have focussed on low variety contexts, such as the design and provision of advanced services in the elevator industry (e.g., Rajala et $\mathrm{al}, 2019$ ), or on the organisations production system and excluded variety introduced to the system by the customer (e.g., Salonen et al, 2018; Kohtamäki et al, 2020), allowing them to transpose the scientific approach to modular design from manufacturing to service. In this study a servitized organisation operating in a high variety environment responds to emergent customer requirements by making physical design changes to products already designed, produced and exchanged with the customer. Our study combines previously separate modularity, paradox and systems theory perspectives to give an alternative explanation of the interplay between firm boundary decisions and the management of both-and efficiency and flexibility in the context of advanced services.

The article is structured as follows. First, we elaborate on our theoretical orientation, establishing a central theoretical proposition within the literature. Research methods are then described, followed by findings from which a process framework for boundary negotiations is presented. Theoretical contributions, managerial implications, and avenues for future research conclude the paper.

\section{Theoretical Orientation}

\subsection{Advanced services and organisational paradox}

Paradoxes are "contradictory yet interrelated elements that exist simultaneously and persist over time" (Smith \& Lewis, 2011: 382). Scholars argue that managing competing (e.g., both-and) organisational paradoxes fosters creativity and sustainable success (Jay, 2013; Ozanne et al, 2016). The effectiveness of a single strategy, as pursued by contingency theory (Voss \& Sousa, 2008), may not be suitable to ensure long term sustainability under increasing conditions of plurality, change and scarcity that render latent paradoxes salient (Smith \& Lewis, 2011). Plurality denotes a multiplicity of views among stakeholders and surfaces competing goals and inconsistent processes; change creates opportunities for sense-making as actors contend with short- and long-term needs; and scarcity relates to resources, brought about by increased complexity and technological innovation (Smith \& Lewis, 2011). A paradox perspective is important for organisations developing more complex business models like advanced service (Kohtamäki et al, 2020). 
Differing ontological positions on paradoxes assume organisational paradoxes are latent and exist prior to an organisations experience of them (Cameron \& Quinn, 1988), are socially constructed (Jarzabkowski et al, 2013), or both (Smith \& Lewis, 2011). Hahn \& Knight (2019) develop a quantum approach, theorising that paradoxes are both inherent and socially constructed, leading them to reconceptualise latency, saliency and persistence. They propose that paradoxes exist in a latent form, but only as potential paradoxes. Paradoxes become salient only when enacted from the pool of potential paradoxes. Further, they are not deterministic, but are shaped by the context within which they are situated. Underpinned by the view that paradoxes are both inherent and socially constructed, Smith \& Lewis (2011) identify four organisational paradoxes: organising, learning, performing and belonging, with tensions arising between each.

Within servitization, the management of both-and efficiency in the production system and flexibility in the provision of customised solutions has been widely discussed (Davies, 2004; Visnjic Kastalli \& Van Looy, 2013). Sitting at the intersection of learning and organising paradoxes, efficiency vs. flexibility reflects tensions between creating practices, routines and capabilities that provide stability, whilst simultaneously providing flexibility to achieve diverse goals (Adler et al, 1999; Smith \& Lewis, 2011). Research proposes that manufacturers can adopt modularity as a coping practice for the management of both-and efficiency and flexibility in the provision of advanced services (Kohtamäki et al, 2020).

\subsection{Modularity, advanced services and efficiency vs. flexibility}

Modular products are developed following Simons (1996) scientific approach to design that advocates the separation of design and context (i.e., where the offering is used). This separation allows organisations to create clear division between the provider and the customer, identify fixed and stable customer requirements, and assume fixed goals in the context of use (Garud et al, 2008). This approach allows organisations to benefit from flexibility in design and economies of scale in production (MacCormack et al, 2001; Salvador, 2007). Specifying the degree of flexibility in design is termed 'planned flexibility' (Gil, 2007) and is a key managerial decision (Engel et al, 2017). When deciding on the degree of planned flexibility, an assumption is made that no rework of the product architecture is required once the design passes to production (Verganti, 1997). Duray et al (2000) find original designs must be implemented in the design phase, where greater degrees of flexibility are available in the specification, whereas in production and use, components used to deliver customisation must be standardised and repeatable to achieve scale economies. Customer requirements must therefore be known or anticipated by the manufacturer prior to production. Once in production, the opportunity for product redesign is significantly reduced as the functional and structural elements of the architecture are frozen pre-production (Henfridsson et al, 2014). Any changes required can be costly and time consuming, particularly if remodularisation of the architecture is required (Lundqvist et al, 1996). 
In OM, efficiency vs. flexibility, often referred to as product variety vs. operational performance (Salvador et al, 2002), was presented as a trade-off decision (e.g., either-or) (Squire et al, 2006), until modularity was identified as a strategy to manage both-and efficiency and flexibility (Salvador et al, 2002). The characteristics of modularity and the design rules that govern the architecture, interfaces and standards, provide the standardisation, formalisation and specialisation needed to ensure efficiency in production, as well as fluidity and independence in design to support flexibility (Baldwin \& Clark, 2000). Duray et al (2000) describe modularity as a "paradox-breaking" technique combining craft and mass production for the design and production of goods within the providers system. This view is shared within service operations literature. Silvestro \& Lustrato (2015) note that the traditional trade-off between variety and volume in the product-process (Ahmed \& Schroeder, 2002) and service process matrices (Silvestro et al, 1992) is inherently paradoxical. They identify modularity as a key capability for organisations to employ in the design and delivery of mass customised services. Peters et al (2020) found modular interfaces play a key role in managing bothand efficiency and flexibility in multi-provider healthcare services. Finally, de Blok et al's (2010) examination of healthcare modularity shows customisation is low in design, but high during production and use. Whilst the opposite of that found in manufacturing by Duray et al (2000), de Blok et al's (2010) results still show that modularity is effective in managing both-and efficiency and flexibility. Scholars align with the view that efficiency and flexibility can be managed via modularity, and there is consensus that the manner in which the paradox becomes salient is dependent upon the context within which it is enacted. This suggests that rather than being deterministic, the use and design of modular offerings to manage both-and efficiency and flexibility is shaped by the context within which they are enacted (Hahn \& Knight, 2019). This ontological understanding of paradoxes is important in providing an understanding of the micro-level management of the both-and efficiency and flexibility (Kohtamäki et al, 2020) within different contexts deploying modular design strategies (Brax et al, 2017).

The view that context shapes the enactment of the tensions between efficiency vs. flexibility is not reflected in the servitization literature, which has transposed the scientific approach to modular design to advanced services. For example, Rajala et al (2019) state that achieve the benefits of modularity "the provider must align a combination of competitive capabilities to manage the complexity of the solutions in the production system" (pp. 631). Studying digital service platforms built on modular architectures, Cenamor et al (2017) state "the platform literature explains how different actors can create value within the organization using platforms" (pp.56). Salonen et al (2018) define modular services "as consisting of a platform that is based on a predefined architecture". In line with these studies, the broader servitization literature finds that modular design: 1) limits variety in the production system by pre-defining the architecture and potential configurations of modules in the design stage; and 2) supports flexibility in design and volume in the production and delivery of advanced services (Davies, 2004; Kowalkowski et al, 2015; Kohtamäki et al, 2020). 
In contrast, Davies et al (2020) argue that the requirements for the scientific approach to modular design conflicts with requirements for advanced service provision, as the latter requires flexibility postproduction. Their empirical results found that product modularity was lost when advanced service providers met emergent customer needs arising from asset use with product upgrade services. Loss of modularity meant the efficiency gains in the design, production and management of the asset are reduced, with implications for through life cost and complexity. Davies et al (2020) did not address organisational paradoxes, but their findings indicate that the tensions between efficiency and flexibility are shaped by operational context and that firm boundary decisions become endogenous to the management of both-and efficiency and flexibility. This is because the boundary between provider and customer becomes fuzzy and intertwined in advanced services (Batista et al, 2017).

Understanding the management of both-and efficiency vs. flexibility therefore requires consideration of the interplay between firm boundary decisions and the management of organisational paradox.

\subsection{Firm boundaries and systems theory}

A firm boundary is defined as 'the demarcation between the organization and its environment.' (Santos \& Eisenhardt, 2005: 491). Decisions regarding the firm boundary definition are strategic, effecting the offering, the ways it is delivered, and the activities performed by the firm and by its suppliers, partners, distributors, and/or customers (Slater, 2006; Baines et al, 2005; Chandraprakaikul et al, 2010).

Within servitization, Salonen \& Jaakola (2015) focus on the definition of the boundary as a discrete structural decision between internal and external resource integration. Santos and Eisenhardt (2009: 641) argue that 'although understanding single-boundary decisions is valuable' research is required that emphasises the 'potential relationships among decisions, the interplay of different boundary-setting mechanisms and the evolution of organizational boundaries'. Building on their work, Huikkola et al (2020) investigate the dynamic interplay among Santos and Eisenhardt's (2005) conceptions as drivers of boundary (re)definition in servitization. Whilst their work considers strategic factors, such as efficiency, power, competence and identity, effecting structural evolution of the firm boundary, there remains a lack of research on the process of change and 'how individual boundary decisions might fit into overall patterns of strategic action' (Santos and Eisenhardt, 2009: 644).

In departing from a strategic view, servitization scholars have explored the implications of defining the firm boundary from a systems and operations perspective (e.g., Batista et al, 2017; Smith et al, 2012). Systems theory, and in particular the concept of the system interface, where inputs and outputs are exchanged between the system and its environment (Weinberg, 2001), provides insight into the relationship between structural boundary decisions and the function of the boundary at an operational level. Jackson (2016) suggests that the interface focuses on the connection between, rather 
than separation of, the system and its environment, which encourages reflection on where the boundary should be drawn.

In advanced services the customer and the provider become jointly responsible for achieving outcomes ( $\mathrm{Ng}$ et al, 2009). As a result, boundary (re)definition is not a simple structural decision dividing internal activities from external, it necessitates changes in the nature of the interface between the provider and customer systems (Batista et al, 2017). Godsiff (2010) uses the analogy of a port and a membrane to describe the structural differences in the interface between delivering a product and delivering a service. For products, the interface between manufacturer and customer acts as a port, a contained place at the firm boundary where exchanges are controlled. To deliver service, the interface is distributed, resembling a membrane where material, people and information transact across the boundary at multiple points. This suggests that in servitization the interface between the provider and customer systems becomes more complex and distributed, with flows of inputs and outputs occurring across a membrane (see figure 1). Negotiating how variety will be matched at the interface with the customer system is a key decision in defining the position and structure of the firm boundary and has implications for the design of the operational system (Godsiff, 2010). Literature drawing upon Ashby's (1969) Law of Requisite Variety shows the provider must be able to amplify or attenuate variety from the external (customer) environment if they are to remain viable in the provision of service (Godsiff, 2010; Ng \& Briscoe, 2012). Remaining viable as an organisation whilst matching the variety introduced following the boundary (re)definition and changes in the structure of the interface is identified as a challenge for servitized manufacturers (Smith et al, 2014), particularly in the context of modular service provision (Davies et al, 2020).

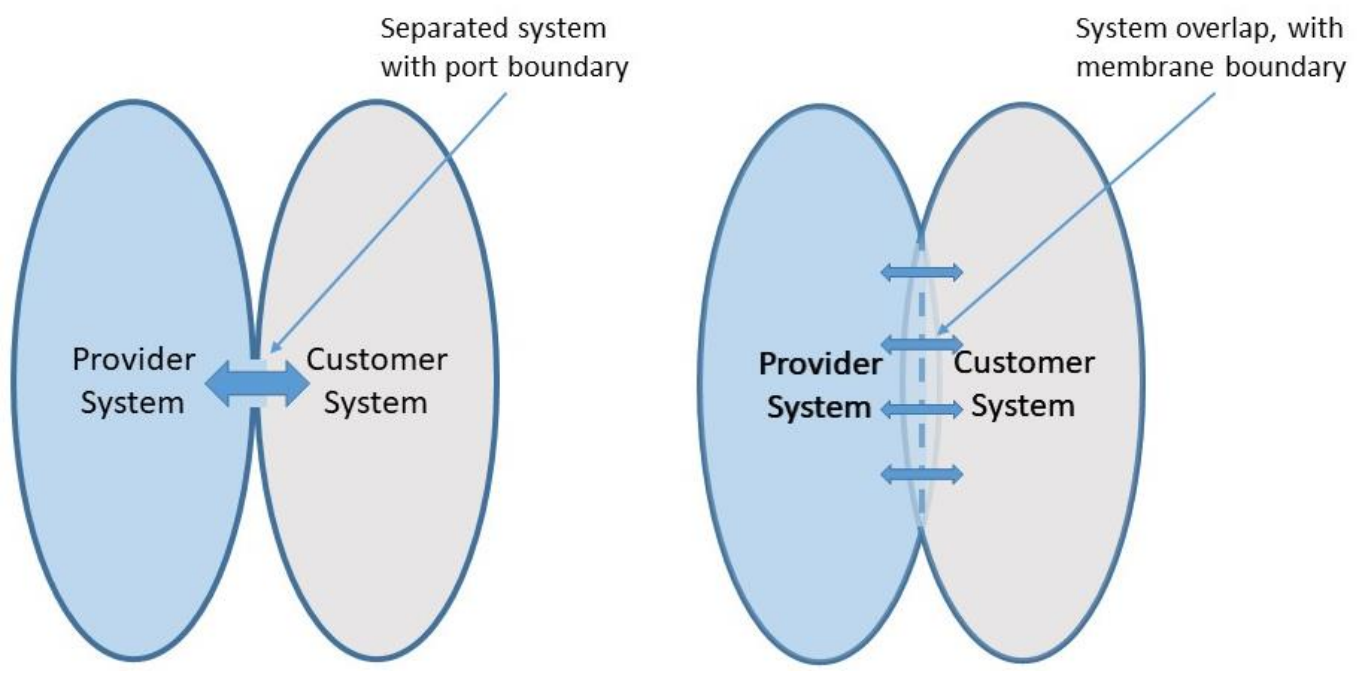

Figure 1. Ports vs. Membranes (adapted from Godsiff (2010)).

The literature review indicates a relationship between firm boundary decisions and the management of tensions between efficiency and flexibility. However, there remains limited work 
addressing the effect of changes in a firm's boundary to include the customer and their context of use (Batista et al, 2017; Valtakoski, 2017) and the management of both-and efficiency and flexibility in advanced services (Kohtamäki et al, 2020). To create understanding as to the interplay between firm boundaries and the management of both-and efficiency and flexibility via modular design, this research seeks to address the following research question:

$R Q$. How do organisations manage the competing demands of efficiency and flexibility in the provision of advanced services?

\subsection{Analytical Framework}

This study draws upon the dynamic equilibrium model for organising proposed by Smith \& Lewis (2011) (figure 2) to act as a guiding framework for our study. The model is made up of a number of components and helps guide our analysis. First, identification and understanding of potential latent paradoxical tensions, and the factors that render the tensions salient. Second, responses that lead to iteration between alternative management strategies. For example, organisations use defence mechanisms either at an individual or organisational level to reduce the degree of threat to the service system (Kohtamäki et al, 2020). In the process of resolving paradoxical tensions actors can get stuck in reinforcing cycles that continue to exacerbate tensions and inhibit change rather than creating the stimulus for change (Smith, 2000). Such cycles can reflect the six defence mechanisms identified by Smith (2000): splitting, regression, repression, projection, reaction and ambivalence. Finally, the framework focusses on paradoxical resolution as a management strategy that leads to the long-term sustainability of the organisation (Smith \& Lewis, 2011).

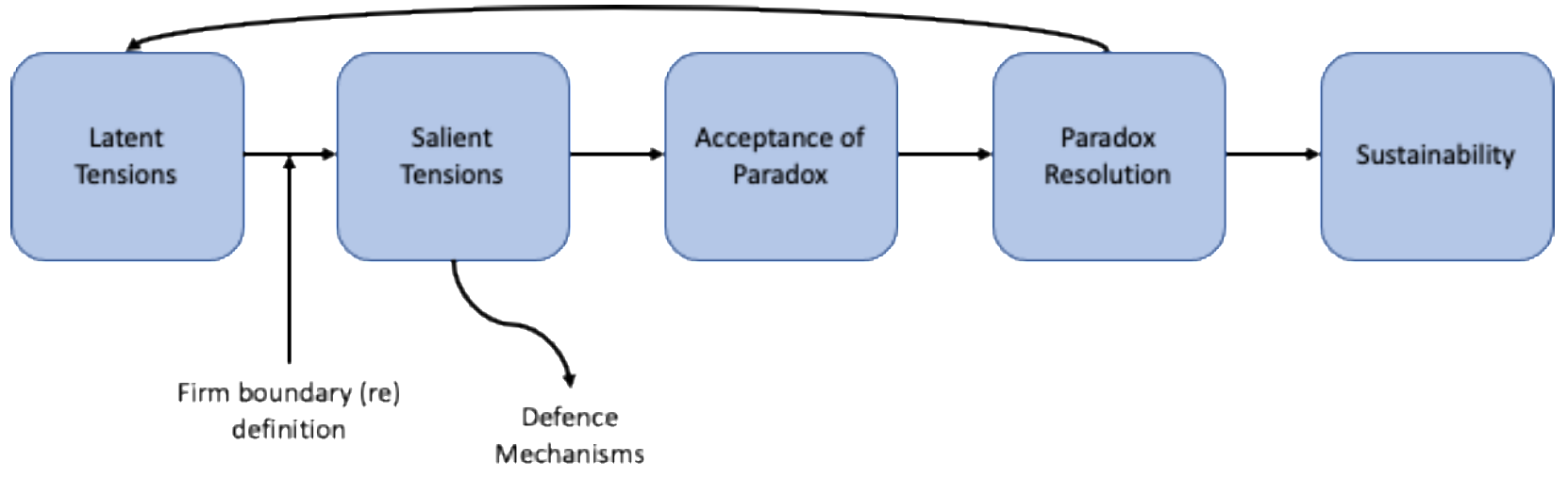

Figure 2. The Dynamic Equilibrium Model for Organizing (adapted from: Smith \& Lewis, 2011). 


\section{Research method}

\subsection{Single case study design}

A single exploratory case study is employed to address the research question. This approach is suitable as understanding of the management of paradoxes within servitization is currently in the development phase (Kohmtamäki et al, 2020; Eisenhardt \& Graebner, 2007). The unit of analysis is the case organisation's engineering design unit, where design changes are made and signed off for production so that they can integrated with the product for use.

\subsection{Case selection}

Criteria for case selection were: 1) the organisation is engaged in the process of servitization and 2) it provides modular, product-centric advanced services. The case organisation is the land subsidiary of a global defence organisation that designs, manufactures and supports a vast range of land combat vehicles through life. The research studied five vehicles from three product families. Product design decisions, including those for product upgrade services, are managed by the engineering design unit and each vehicle has a platform manager with oversight of the vehicles design and management. The case organisation is an 'industrializer' that meets diverse customer requirements through the mixing and matching of modules (Kowalkowski et al, 2015). The organisation has developed customer responsive product upgrade services, defined as advanced services that "match customized customer requirements arising throughout product usage" (Sousa \& da Silvieira, 2017, pp. 454), and these are provided for the vehicles studied.

Within the UK defence industry, product upgrades are requested through a process called Urgent Operation Requirements (UOR), where requirements arise from previously un-resourced and emergent capability gaps revealed during current or imminent military operations. UORs ensure fit between product functionality and context of use, and are addressed by the provider's product upgrade services.

\subsection{Data collection}

Research investigated the management of both-and efficiency and flexibility when implementing design changes to the vehicle's architecture (functionality) through product upgrade services. This study analyses 60 design changes, implemented when the vehicles were in active military conflicts between 2001-2014, and the managerial decisions around them. All vehicles studied were subject to UOR product upgrades that required, for example, the redesign of their protection systems, weapons systems and environmental capabilities. The research itself took place between 2014 and 2018.

Two rounds of semi-structured interviews were conducted. To avoid subjectivity and bias, respondents were sought from a broad spectrum of roles within the organization. Secondary data was used to triangulate findings (Eisenhardt and Graebner, 2007). Table i presents an overview of all data collected. An interview protocol (appendix A) with three major themes was used as a guide (Yin, 2003). 
This covered the process and reasoning behind UORs, vehicle design and modularity, technology use and the design and manufacturing capabilities required for delivering UORs. The research design actively encouraged departure from the set questions by prompting informants to discuss related information as it emerged (Eisenhardt \& Graebner, 2007). Two members of the organization were project champions from the start, coordinating links between organization staff and researchers. Project champions supported the recruitment of key informants and supported identification and provision of relevant documents.

$<$ Please insert table i here $>$

\section{Table i. Overview of study data.}

The first round of interviews were conducted with engineering staff involved in the design changes and service staff who had visibility of the customers product use. The second round of interviews was with senior members of the organisations staff. The same interview protocol as round 1 was used, with the addition of Design Structure Matrix (DSMs) within the interviews. DSMs are square matrixes that display relationships between components, modules and subsystems of a system in a visual and analytically advantageous manner (Browning, 2001) [for full details on DSM construction and analysis of the case companies' vehicles, see Davies et al (2020) where the DSMs were developed for as part of another study]. DSMs were used within the interviews as epistemic objects (Ewenstein \& Whyte, 2009), to engage the interviewee in a reflective process of creative problem solving from which we capture detailed knowledge. DSMs proved effective as epistemic objects within the interview protocol. The organisation had not used DSMs as part of their design process and their use engaged and focussed interviewees by providing a structured representation of their design decisions made during the period 2001-2014. This allowed researchers to capture detailed knowledge on details of the decision process with respect to design changes and product architecture, guiding participant responses by engaging them with actual data from their vehicles.

\subsection{Data analysis}

To address the research question, data were coded and analysed by the lead researcher using thematic analysis, checked by a second researcher, and discussed with two other members of the research team (Braun \& Clarke, 2006). Disagreements were resolved through group consultation and further scrutiny of the coded data. Table ii details the analysis procedure. In line with Raja et al (2018), 
the additional step "fieldwork preparation" precedes steps defined by Braun \& Clark (2006). Following Eisenhardt (1989), research adopted an iterative approach, moving between emerging data and the extant literature. Through this approach, the combination of theoretical and empirical knowledge allowed the process model to emerge (see figure 3 ).

\author{
$\langle$ please insert table ii here $>$
}

Table ii. Data analysis procedure (adapted from Braun \& Clark, 2006; Raja et al, 2018).

\title{
3.5 Assessment of research quality
}

To ensure robustness of the findings and removal of subjective judgements, the research made consistent use of data triangulation (Eisenhardt \& Graebner, 2007). Obtaining consistent information from multiple sources of evidence indicates convergent validity and protects against researcher bias and subjectivity (Goffin et al, 2019). Efforts to establish a clear chain of evidence were made via transparency of the research design and clear presentation of data to show how conclusions were drawn (Goffin et al, 2019) ensuring the criteria of confirmability was satisfied. To ensure credibility, the first author presented the research to the two project champions in the first, second and final year of the project. When clarifications were needed with respect to the data, researchers approached key informants. A final report was provided to the project champions at the end of the project for review and feedback. These activities provided detailed feedback from key informants, ensuring congruency between information obtained and researchers' interpretation of the phenomenon (Voss et al, 2002). With respect to transferability, this research describes in detail the research context and the assumptions underlying the research, providing the relevant information needed to transfer the approach to a different context.

\section{Findings}

The findings present insights into the process of boundary negotiations for the design of efficient and flexible modular systems within the context of advanced services that emerged inductively from 
the analysis. The findings are presented in three parts, each corresponding to one of the three phases for boundary negotiations; boundary ambiguity, boundary defences and boundary re-definition (figure 3 ). 


$$
0^{e^{6}}
$$




\subsection{Phase 1: boundary ambiguity}

Initial examination of the product upgrade services background revealed that the decision to provide the advanced service was driven by customer need to maintain viability of their system. During active conflict the customer recognised that the context within which the products are used evolves over time. Changes in context means functionality available may no-longer be appropriate for use context, providing sub optimal outcomes for military operations. Viability of the customers system is threatened each time the context of use changes as it creates gaps between what the product was designed for and what it is used for. This is reflected in published customer and UK government documents, where the reasons for requesting a UOR can be classified into five categories, with the first two relevant to this study:

“a. To provide an operationally specific capability (e.g., environmental protection).

b. To fill a previously unidentified capability gap (e.g., threat change)."

The underlying philosophy of UORs defined by the customer is also shared by the provider, where an engineer notes that the philosophy behind UORs is:

"to enable them [customer] to deploy equipment which is fit for purpose for the immediate need for the immediate missions in an accelerated time frame".

From the perspective of the provider, offering product upgrade services required a (re)definition of the firm's boundary of responsibility as they shift from selling products to offering advanced product upgrade services. (Re)defining the firm boundary resulted in the provider being exposed to contextual variety from the customer's context of use.

Our findings indicate that variety from the customers system entering the providers system through product upgrade services has implications for the provider's effective management of both-and efficiency and flexibility at the operational level. Informants reported that providing product upgrade services and responding to emergent requirements required them to emphasise flexibility over efficiency to ensure viability of the customers system. This resulted in a loss of modularity within the product architecture for the vehicles modified. For example, during a during a vehicle tour with a platform manager and project champion, they explained how each product upgrade (e.g., response to a UOR) potentially resulted in a loss in modularity within the products architecture. In a follow up interview with the platform manager, they noted that that one of the reasons for this was that they could not plan around future designs as it was not possible to know when or what the emergent requirements would be: 
“... the timescales of some of the UORs they're very ad hoc and they're very bitty as well. So one week you can be doing a modification to a turret and do it in a way that meets that timescale; it may not be the way that you would like to do it and six months later someone says, 'Well actually, I'd like this modification', we didn't know that, we'd have done that bolt on instead of welding it on.".

The findings highlight that planning designs or specifying modular interfaces without knowing what the next requirement will be creates design challenges and contributes toward the loss of modularity in the product architectures. Another informant highlights that the way in which they had to design the product upgrades had implications for through life costs as flexibility was prioritised over efficiency in the design of the product upgrades:

"we managed to implement the design changes the customer wanted, but the timescales they provided and the legacy fleets we work with meant they were not designed as we would like from a through life cost perspective. I expect the through life costs will be high."

The amplification of variety from the customers system through product upgrades in the providers system shows that the management of the efficiency vs. flexible paradox has become salient as the scientific approach to modular design the provider historically relied upon was no-longer functional. Plurality manifested in the competing goals and inconsistent processes between the scientific approach to modular design and the requirements of advanced service provision. The former requires functionality to be defined pre-production and the latter requires capabilities to respond postproduction. Further to the comments made by the platform managers with respect to the loss of modularity, informants from the engineering staff highlighted that the scientific approach to modular design is not suited to post-production design changes because of the cost and complexity associated with implementing changes that extend beyond the original specification:

"the whole thing about specifying the requirement to deliver an end product is very long, 15 years maybe, 10 to 15 years, and ... 20 percent of the time you've got 90 percent of the cost and therefore changing the capability after that point is a bit of a nightmare".

This is corroborated with another member of the engineering staff when discussing modularity and UORS, where they state:

"So it's legacy platforms. Changing stuff is quite difficult and quite costly, quite timely"

In making the decision to let variety enter the providers system, the organisation was faced with conflicting short- and long-term needs. The short-term need was satisfying the customer and receiving 
revenue from the product upgrade service. The long-term need was the efficient management of both efficiency and flexibility of the vehicles, which could have been maintained if they rejected UOR requests outside of pre-determined modular interfaces. A platform manager recognised the challenge, stating:

“... things like...interchangeability, there may be some relaxation of things like that because we say, 'Look, we understand that there may be complexities further down the stream but this is to get round an immediate problem that we have to get round', so there are all those considerations.".

Rejecting customer UOR requests is not a viable option if the provider is to remain financially viable. If they did not respond to the UOR requests within timeframe they may be removed from contracts for future product upgrades, which has implications for provider viability, as noted by a platform manager:

"we've been told that if we can't meet that requirement then we will be pulled back [from supporting product upgrades] and, of course, if you're pulled back you're finished, you know, if you're not in operation then that has an adverse effect on business as well."

Focussing on short term goals and emphasising flexibility over efficiency in the provision of product upgrade services characterises the defence mechanism of splitting (Smith, 2000).

Finally, our findings indicate that limited lead times (temporal scarcity) contributed to the saliency of the efficiency vs. flexibility paradox in the provision of product upgrades services. Temporal scarcity reflects the immediate need for capability insertion into the customer's context of use and the time restrictions this placed on the provider to design and deliver the product upgrade. Temporal scarcity was particularly detrimental for the design phase, which is important for the integration of modular change that extends beyond the original specification (Lundqvist et al, 1996; Davies et al, 2020), as reflected in the following engineer extract:

“...you're always hampered by the lead time to make things... if it's going to take four weeks to make something it's going to take four weeks to make ... you always end up having to plan back from that which inevitably squeezes the engineering time to a minimum because you've always got this hard line from the customer which says we need this vehicle in theatre by whatever date and then you've got to work back from that and you assume it's going to take that long to make something so therefore you've only got that length of time to design." 
The findings show how managers cope with tensions between efficiency and flexibility, rendered salient by the factors of plurality, change and scarcity. They deliberately lose modularity, allowing the boundaries of provider and customer systems to overlap and form a more holistic, complex service system, as opposed to the traditional systems perspective presented in the servitization literature that places the customers external to the providers system ( $\mathrm{Ng}$ et al, 2009; Batista et al, 2017). The overlap is tolerated primarily to enable the system as a whole to be effective. In essence, the firm was willing to soften its boundary of responsibilities by allowing a high degree of ambiguity in delivery roles, allowing variety to permeate the interface between provider and customer. Findings indicate an interplay between the firm boundary of responsibility and the management of the efficiency vs. flexibility paradox. Introducing ambiguity at the boundary of responsibility serves as a coping mechanism for both parties to negotiate the tensions, instead of the firm taking unilateral decisions.

Boundary ambiguity creates situations where the firm or customer can take responsibility for delivery decisions, but specific responsibility at any point in time is deliberately unspecified, reflecting both parties willingness to be pragmatic. In other words, ambiguity enables situational and contextual value to emerge from the tensions between effectiveness and flexibility.

\subsection{Phase 2: boundary defences}

Following phase 1, the provider focussed on boundary defences to support short term viability of their system. To mitigate the risks associated with the salience of the paradox and the inability to manage both-and efficiency and flexibility during the provision of product upgrade services, our findings indicate two primary defences for sustaining short term viability of the providers system: architectural change and stakeholder negotiation.

\subsubsection{Architectural change}

During the customer's military campaign, a UOR request from the customer required the core platform of one of the vehicles to be modified. Whilst only happening to one vehicle during the customer's campaign, this type of request allowed the provider to modify the underlying structure of the architecture, the way modules interact with the core platform and to specify new design rules. This allowed previous product upgrades, for which a number had been delivered, to be re-integrated in a modular fashion. Table iii shows the vehicle functionality pre-conflict, during conflict with UORs changes that were implemented as individual (often non-modular) changes, and post architectural change where the core platform was redesigned and past UORs standardised and/or optional extras incorporated into the products functionality (re-modularised). 
< insert table iii here >

Table iii. Pre, during and post architectural chang $e^{I}$

\footnotetext{
${ }^{1}$ For original design and architectural change, 0 reflects an 'optional' add on e.g., a modular augmentation.
} 
A platform manager noted that UORs that permitted architectural change also provided them with the opportunity to embed further planned flexibility to accommodate anticipated demand they felt may emerge in the future:

“...when we've had the opportunity to change the whole structure we've thought ... in the future somebody might want a rear mounted (modification), so we make sure that ... we're not just going to weld a box on, we bolt a box on to start with and we make sure it's got a bolt on roof, so you take that off and you can interface whatever you like to that. We did that on (one vehicle) and before we even finished the UOR another UOR had appeared... so we were able to take that top plate out knowing it had the correct interface detail for the (modification). So we do try and put a bit of thought in for the future just knowing that you never really know what's coming next."

To implement architectural change, the provider followed the scientific approach to modular design, allowing them to re-balance efficiency and flexibility in their system. This rebalance was only temporary as the customer was still involved in active conflict, resulting in further complexity entering the providers system via UORs that did not align to the products new design rules. Allowing these further emergent requirements meant that the provider, as holder of design authority, was willing to negotiate their products architecture through the continued use of the defence mechanism of splitting, emphasising flexibility over efficiency.

\subsubsection{Stakeholder negotiation}

Stakeholder negotiation was identified as a dialogue between the provider and the customer to optimise the short-term viability of their respective systems. For the provider, this reflected the need to re-coup the costs of rapid product development and through life cost implications of emphasising flexibility over efficiency in their operational system whilst remaining in a position to deliver the product upgrade. For the customer, this was receiving a product upgrade to fill capability gaps within their context of use. There were two primary negotiations between the stakeholders: service cost and in-service life.

The first stakeholder negotiation, service cost, reflects the premium price the customer pays for the product upgrade service when compared with the price they would pay for normal development cycle costs. During conflict, the customer has greater flexibility to spend if the need for a capability is there. This flexibility was built in to accommodate 1) the speed at which they require product upgrade and 2) because the change does not align to the fixed specification provided during the original design and production of the asset. This gave the provider opportunities to re-coup some of the costs associated with accommodating emergent requirements. A platform manager highlighted this and stated: 
"What it means for a supplier is that they are generally in a more favourable position in terms of covering their costs because the pricing arrangements are, I think, made a little bit more flexible to allow a supplier to do what's needed and also to flex because typically in a normal contract the [customer] would be pressured to maintain their requirement stable rather than modifying it midcontract because there's costs associated with that. If you have an arrangement where the supplier costs can be met then you can have a much better partnering to satisfy a given need."

The ability to price higher for a product upgrade meant higher revenues than normal could be received, mitigating some of the through life costs expected due to the loss of modularity.

The second stakeholder negotiation, in-service life, captures instances when the provider cannot guarantee delivery of product upgrade within timescale whilst complying with all through-life engineering standards for product upgrades during normal product life cycles (e.g., 20 years +). The full engineering trials guaranteeing a service life of 20+ are labour intensive and time consuming, and often incompatible with the delivery deadline set by the customer. Given this, the provider and customer negotiate what trials are required to ensure a safe minimum viable product that satisfies a UOR for a certain period of in-service life. A platform manager described this dialogue with the customer:

“...what you say is, "Well look, you know, that is a UOR that's going to last for 12 months, no longer... and in many ways they say, "Well, look, the UOR, would you rather go out with that UOR fitted though it's not completely tested or would you rather go out without it? "And they would rather go with it generally."

Should the need for a product upgrade to remain after the safety case expires, further engineering trials are required. Otherwise a UOR may be removed from the product as the customer context has changed such that the functionality is no longer needed. Removal of the UOR could mean some of the modularity lost could return. However, often multiple UORs are implemented, so even if one is removed after a period of time it may have impacted the design of subsequent UORs. This is reflected in a previous quote that described the implications of the emergence and timescale of the UORs as ad hoc and bitty.

Together, architectural change and stakeholder negotiation form a further part of boundary negotiations, allowing parties to negotiate such that any loss of modularity can be restored, minimised or compensated for in the provision of product upgrade services. Whilst these two boundary defences allowed both the provider and customer to optimise their respective systems viability in the short term, longer-term solutions for responding to emergent requirements from the customers systems were needed. 
Phase 3 focusses on paradox resolution whereby the providers practices for the management of bothand efficiency and flexibility in the provision of product upgrade services must align with the structure and function of the firm boundary. The need for alternative means to satisfy emergent requirements was identified by both the provider and customer following the end of the customer's period of active military conflict and began re-evaluating future needs. A customer document reporting on the future character of conflict concluded that military campaigns would be increasingly asymmetric and impossible to predict, requiring the military to develop more agile capabilities alongside industry partners, as evidenced in the documentation stating:

"Increasingly, we will find ourselves reliant on industry for support, both in the home base and in theatre, if we are to be adaptive."

Further, in the context of delivering product upgrades to adapt or modify military equipment during an active campaign, the customer recognised that current response times were sub-optimal. Improvements would require provider and customer systems to integrate more closely to develop new production capabilities. The customer funded industry projects exploring technological solutions that could provide them both efficient and flexible capability, primarily through product upgrade services or similar mechanisms. Additive manufacture (AM) (3D printing) was one such option the customer explored:

\section{"The current response time to develop and deliver a novel concept to theatre is not optimal. This} challenge seeks to demonstrate how additive manufacturing may be used to increase re-

configurability in military systems. We want to understand whether additive manufacturing could be used to rapidly build, adapt or modify equipment to provide enhanced functionality."

\subsubsection{Strategic alignment and operational capabilities}

To provide product upgrades whilst managing both-and efficiency and flexibility the provider needed to develop new operational capabilities. Following their decision to provide product upgrade services a splitting strategy was employed, prioritising flexibility over efficiency. This allowed the provider to support the customers system during an active conflict, but long term the approach was not viable for either party. A member of the engineering staff identified a need for new operational capabilities driven by technology, additive manufacturing, as part of a hybrid system:

“..,we're expecting quite a lot of disruptive change, which has been driven by technology, we'll have to put much more flexibility, much more adaptability as well, into the designs of our future products in order to meet these changing requirements. Now the reality is, that I think if the two approaches 
[AM and traditional manufacturing] are mentioned, ... the likelihood is there's going to be some hybrid model of the two where you can produce products which are adaptable, which are flexible, and at the same time, can produce new products or even modify existing ones for a more UOR type approach. For that you need engineering capabilities of a new order."

The development of new operational capabilities was expected to create strategic alignment between the provider's service delivery system and the firm boundary. New capabilities would allow variety to permeate the provider firm boundary without introducing increased cost or complexity, thus negating the need for further boundary negotiation. When delivering product upgrade services during the conflict studied, informants recognised that the existing approach to designing and delivering product upgrade services did not align with the strategic orientation of the business model. Informants saw that the existing delivery system relied upon traditional manufacturing and supply chain processes that limited their ability to be both efficient in product upgrade delivery and flexible in the design of modular upgrades. Comparing their existing delivery system to the capabilities they were developing with AM, the technology lead stated:

'It's not just whether the current manufacturing approach is as fast, it is the end to end process around that part...If I want a spare part that's made as a cast part... what I've got to do is raise the order...they've then got to man up the foundry and there might be minimum order quantities, so they wait until they've got enough orders to warrant running up the foundry so you've got, potentially, an indeterminate lead time. The difference [from $\mathrm{AM}$ ] that you get is the flexibility in lead time and responsiveness. So can AM help to increase the operational flexibility, which, in turn, will help you respond better to an unidentified or emerging threat? Yes.

AM technology also had implications for how the provider could manage both-and efficiency and flexibility in the design of their products. The affordances provided by both AM and modular design allow for new operational capabilities to produce bespoke parts that can be integrated into a modular architecture. An engineer explained:

'Modularity enables you to be quicker. The cumulative effect of AM, in combination with a modular architecture, is probably greater than the sum of the parts because modularity will give you benefit, AM will give you benefit. Putting the two together, meaning you can quickly manufacture bespoke parts, to a particular threat, in a particular environment, on a particular vehicle, for a particular modular location, that's going to mean you're more agile'

Phases 1 and 2 found that the interaction of contextual variety across the boundary from the customers system into the provider system threatened the modular design architecture and with it, the 
viability of the providers system. The provider assets were designed against a different boundary condition: exchanges via ports between systems. Phase 3 finds that the provider needs to develop the capabilities of their product and operational system to achieve strategic alignment with the objectives of the advanced services they are providing. This entails meeting the variety of emergent demands from the customers system with an economically viable product upgrade service. Technology coupled with historical design approaches are being explored as a means to support the re-modularisation of delivery systems towards an aligned service outcome, where both product and service components are designed against the same functional boundary.

\section{Discussion}

\subsection{Theoretical Contributions}

This research makes several contributions to the modularity and servitization literature explaining the interplay between firm boundary decisions and the management of both-and efficiency vs. flexibility.

First, we provide insight into the firm boundary as a coping mechanism for the management of both-and efficiency and flexibility. Prior literature has tended to underplay the relationship between firm boundary decisions and the management of organisation paradox. We argued that this stems from the fact that literature has historically viewed the (re)definition of the firm boundary as a discrete structural decision (e.g., Santos \& Eisenhardt, 2009; Chandraprakaikul et al, 2010; Salonen \& Jaakola, 2015; Huikkola et al, 2020). This ignores the functional role the interface plays in protecting a providers system from customer induced contextual variety at the operational level. Our research draws upon several studies within the servitization literature that adopts a systems theoretical lens (e.g., Ng et al, 2009; Smith et al, 2014; Batista et al, 2017) and finds that the function of the boundaries interface between provider and customer systems acts as a coping mechanism for the management of both-and efficiency vs. flexibility at the operational level. Specifically, we show that when the provider and customer systems overlap to form a more holistic service system, the structure of the interface changes from a port to a membrane. This change in structure allows variety to permeate the providers systems and creates challenges for managing efficiency vs. flexibility when using the coping practice of the scientific approach to modular design (Kohtamäki et al, 2020). Whilst the function of the interface between the provider and customer has been considered within servitization, it is not considered in the context of managing organisational paradox or firm boundary decisions. By integrating paradox and systems theory, this article generates novel insight into the relationship between firm boundary decisions and the management of both-and efficiency and flexibility in the provision of advanced services. Specifically, this research shows that the function of the interface between the provider and customer shapes the way in which the tensions between efficiency and flexibility become salient in the provision of advanced services (Hahn \& Knight, 2019). 


\section{Proposition 1a. The firm boundary and the management of both-and efficiency and}

\section{flexibility are interdependent.}

\section{Proposition 1b. The function of the interface between provider and customer systems has implications for the management of both-and efficiency and flexibility.}

Second, our paper contributes to extant literature by bringing together modularity in the delivery advanced services, the tensions between efficiency and flexibility, and how boundary negotiations between provider and customer serve as mechanisms for paradox resolution. Research is limited into the process of firm boundary change (Santos and Eisenhardt, 2009; Huikkola et al, 2020), and the management of organisational paradox (Kohtamäki et al, 2020). Through the integration of systems, paradox and modularity theory, this article offers an in-depth perspective on the process of change following the (re)definition of the firm boundary and the saliency of tensions between efficiency and flexibility. Our process model depicts three phases of boundary negotiations: boundary ambiguity, boundary defences and boundary re-definition. These phases play a critical role in determining how a servitized provider manages both-and efficiency and flexibility in the provision of advanced services. Further, this research identifies relationships amongst decisions, practices for the management of bothand efficiency and flexibility and how they influence the evolution of organisational boundaries within these three phases. Specifically, in pursuing the management of both-and efficiency vs. flexibility in the provision of advanced services, the provider had to negotiate and make decisions around a) the boundary of their responsibility within the phase 'boundary ambiguity', b) changes to product architecture and expected life-cycles with the customer within the phase 'boundary defences' and c) the future nature of the boundary between the provider and customer within the phase 'boundary alignment'. Our findings provide a systematic illustration of each form of negotiation through an indepth case study and reflect a theoretical contribution to the servitization literature and the delivery of advanced services. In addition to addressing the call from Santos \& Eisenhardt (2009) for further research into the relationships between management practices, decisions and boundary evolution, our article also extends the work of Salonen \& Jaakola (2015) and Huikkola et al (2020). We do this by moving beyond firm boundary as discrete structural decisions, to provide insight into the functional role of the firm boundary and relationships that exist amongst decisions and the firm boundary evolution.

Proposition 2a. If tensions between efficiency and flexibility become salient, the provider and customer must negotiate the management of variety at the boundary of their systems. Proposition 2b. Boundary negotiation for the design of efficient and flexible modular systems contains three distinct phases; boundary ambiguity, boundary defences and boundary alignment.

Finally, our work extends that of $\mathrm{Ng} \&$ Briscoe (2012) and Smith et al (2014) by considering the relationship between the providers design activities and operational system and the customer's context of use. Smith et al (2014) postulate that a holistic service system that includes the provider and the customer would not be viable if the design of the product did not consider the interaction with 
contextual outcomes from the customers system. $\mathrm{Ng} \&$ Briscoe (2012) suggest that products designed against a different set of firm boundaries (e.g., exchange) restrict the viability of the service system as products have fixed utility at the point of use. Our article extends their work by showing that treating the product as a separate entity to the service creates misalignment between the objectives of the service system and the systems components i.e., the product and the service. We have shown that failure to consider contextual variety in the design of the product threatens firm viability when they transition to service, as the scientific approach to modular design is not conducive to absorbing emergent requirements from use.

\section{Proposition 3. The scientific approach to modular design is not suited to the management of both-and efficiency and flexibility in high variety advanced services.}

\subsection{Managerial Implications}

This research has indicated the complexity of managing organisational paradox and specifically, the tensions between efficiency vs flexibility, in high variety contexts. We show that if organisations shift from selling product to providing advanced service, managers cannot simply treat service as an addition to their product offerings. Tensions between efficiency vs. flexibility cannot continue to be managed within the existing operational system as it was designed against a different firm boundary, product exchange. The firm boundary changes with advanced service provision and factors from outside of existing boundary enter the system, potentially rendering latent paradoxes salient. Addressing paradox requires new approaches if the viability of the new customer/provider system is to be maintained. For organisations new to servitizing, or currently experiencing challenges in managing both-and efficiency and flexibility, our findings indicate the extent of the challenges they face and offer some guidance as to how they can resolve these challenges through a process of boundary negotiations. Designing a delivery system that is able to manage both-and efficiency and flexibility in such dynamic environments requires considerable expertise and the development of new operational capabilities that are unlikely to already exist in a product-orientated organisation.

\section{Limitations and Future Research}

This study has limitations that should be considered. First, whilst the findings motivate new ideas and recognise weaknesses in our existing paradigmatic assumptions, it is difficult to generalize the results beyond the empirical setting presented. Results should primarily be considered applicable to contexts with similar conditions. Replicate studies, using our research design would verify the results with multiple cases in either the same or other industries. Second, whilst the research provided insight from the customer perspective via secondary data, we did not collect interview data directly from the customer. Further studies should seek to take a holistic approach and investigate the phenomena from both the provider and customer as recommended by the literature (e.g., Smith et al, 2014; Sjödin et al, 2020). 
Our research, which highlights the interplay between firm boundaries and the management of organisational paradoxes, provides a beneficial path for future research. For example, the present study suggests further research questions regarding firm boundary decisions, paradox management and the role these play in the success or failure of a servitizing manufacturer. This is particularly fruitful when the boundaries between provider and customer systems overlap to form a more holistic, complex service system. However, as we only studied a single case, we were not able to study cases that did not successfully participate in boundary negotiation. Future research should consider multiple cases considered successful and unsuccessful in boundary negotiations to understand the implications this has for servitization and deservitization. Further, whilst our research highlights the importance of understanding this interplay between firm boundary decisions and paradox management, we only explore this in the context of a single case and efficiency vs. flexibility. Further studies should explore the interplay between firm boundary decision and paradox management in the context of other organisational paradoxes, such as control vs. autonomy or exploration vs. exploitation.

\section{References}

Adler, P. S., Goldoftas, B., \& Levine, D. I. (1999). Flexibility Versus Efficiency? A Case Study of Model Changeovers in the Toyota Production System. Organization Science, 10(1), 43-68.

Ahmad, S. \& Schroeder, R.G. (2002). Refining the product-process matrix, International Journal of Operations \& Production Management, 20(1), 103-24.

Ashby, W.R. (1969). Self Regulation and Requisite Variety, in Emery, F.E. (Ed.): Systems Thinking, Penguin Books, Middlesex, 105-124.

Baines, T.S., Kay, G., Adesola, S., \& Higson, M. (2005). Strategic positioning: An integrated decision process for manufacturers, International Journal of Operations \& Production Management, 25 (2), 180-201.

Baines, T., \& Lightfoot, H. (2014). Made to Serve: What it takes for Manufacturers to Compete, Wiley.

Baldwin, C. Y., \& Clark, K. B. (2000). Design Rules: The Power of Modularity. The MIT Press.

Batista, L., Davis-Poynter, S., Ng, I., \& Maull, R. (2017). Servitization through outcome-based contract - A systems perspective from the defence industry. International Journal of Production Economics, 192(October 2016), 133-143.

Braun, V., \& Clarke, V. (2006). Qualitative Research in Psychology Using thematic analysis in psychology Using thematic analysis in psychology. Qualitative Research in Psychology, 3(2), 77-101.

Brax, S.A., Bask, A., Hsuan, J. \& Voss, C. (2017), Service modularity and architecture - an overview and research agenda, International Journal of Operations and Production Management, 37(6), 686-702. 
Browning, T. R. (2001). Applying the Design Structure Matrix to System Decomposition and Integration Problems: A Review and New Directions, IEEE Transactions on Engineering Management, 48(3), 292-306.

Cameron, K., \& Quinn, R. (1988). Organizational paradox and transformation, Ballinger.

Cenamor, J., Rönnberg Sjödin, D., \& Parida, V. (2017). Adopting a platform approach in servitization: Leveraging the value of digitalization. International Journal of Production Economics, 192(November 2015), 54-65.

Chandraprakaikul, W., Baines, T.S., Lim, R.Y., \& Sakburanapech, A. (2010). Success factors in a forming strategic positioning of manufacturing operations within global supply chains, Proceedings of the Institution of Mechanical Engineers, Part B: Journal of Engineering Manufacture, 831-844.

Davies, A. (2004). Moving base into high-value integrated solutions: A value stream approach. Industrial and Corporate Change, 13(5), 727-756.

Davies, P., Parry, G., Alves, K., \& Ng, I. C. L. (2020). How Additive Manufacturing allows Products to Absorb Variety in Use: Empirical Evidence from the Defensive Industry. Production Planning and Control, In Press: https://doi.org/10.1080/09537287.2020.1810763

Eisenhardt, K. M. (1989). Building theories from case study research. Academy of Management Review, 14(4), 532-50.

Eisenhardt, K.M., \& Graebner, M.E. (2007). Theory building from cases: opportunities and challenges. Academy of Management Journal, 50(1), 25-32.

Engel, A., Browning, T. R., \& Reich, Y. (2017). Designing Products for Adaptability: Insights from Four Industrial Cases. Decision Sciences, 48(5), 875-917.

Ewenstein, B., \& Whyte, J. (2009). Knowledge practices in design: The role of visual representations as 'epistemic objects.' Organization Studies, 30(1), 7-30.

Garud, R., Jain, S., \& Tuertscher, P. (2008). Incomplete by design and designing for incompleteness. Organization Studies, 29(3), 351-371.

Gil, N. (2007). On the value of project safeguards: Embedding real options in complex products and systems. Research Policy, 36(7), 980-999.

Godsiff, P. 2010. "Service Systems and Requisite Variety.” Service Science 2 (1-2), 92-101.

Goffin, K., Åhlström, P., Bianchi, M., \& Richtnér, A. (2019). Perspective: State-of-the-Art: The Quality of Case Study Research in Innovation Management. Journal of Product Innovation Management, 36(5), 586-615.

Green, M. H., Davies, P., \& Ng, I. C. L. (2017). Two strands of servitization: A thematic analysis of traditional and customer co-created servitization and future research directions. International Journal of Production Economics, 192(December 2015), 40-53.

Hahn, T. \& Knight, E. (2019), The ontology of organizational paradox: a Quantum approach, Academy of Management Review, In Press: https://doi.org/10.5465/amr.2018.0408 
Henfridsson, O., Mathiassen, L., \& Svahn, F. (2014). Managing technological change in the digital age: The role of architectural frames. Journal of Information Technology, 29(1), 27-43.

Huikkola, T., Rabetino, R., Kohtamäki, M., \& Gebauer, H. (2020). Firm boundaries in servitization: Interplay and repositioning practices, Industrial Marketing Management, 90(October), 90-105.

Jackson, M. C. (2016). Systems thinking: Creative holism for managers. Chichester, England: John Wiley.

Jarzabkowski, P., Lê, J. K., \& Van de Ven, A. H. (2013). Responding to competing strategic demands: How organizing, belonging, and performing paradoxes coevolve. Strategic Organization, 11(3), 245-280.

Kohtamäki, M., Einola, S., \& Rabetino, R. (2020). Exploring servitization through the paradox lens: Coping practices in servitization. International Journal of Production Economics, Vol, 26 (August).

Kowalkowski, C., Gebauer, H., \& Oliva, R. (2017). Service growth in product firms: Past, present, and future. Industrial Marketing Management, 60, 82-88.

Kowalkowski, C., Windahl, C., Kindström, D., \& Gebauer, H. (2015). What service transition? Rethinking established assumptions about manufacturers' service-led growth strategies. Industrial Marketing Management, 45(1), 59-69.

Lewis, M. W. (2000). Exploring Paradox: Toward a More Comprehensive Guide. The Academy of Management Review, 25(4), 760.

MacCormack, A., Verganti, R., \& Iansiti, M. (2001). Developing products on "Internet time": The anatomy of a flexible development process. IEEE Engineering Management Review, 29(2), 90104.

Ng, I. C. L. (2014). Creating New Markets in the Digital Economy. Cambridge University Press.

Ng, I. C. L., Maull, R., \& Yip, N. (2009). Outcome-based contracts as a driver for systems thinking and service-dominant logic in service science: Evidence from the defence industry. European Management Journal, 27(6), 377-387.

Ng, I., \& Briscoe, G. (2012). Value, Variety and Viability: New Business Models for Co-Creation in Outcome-based Contracts. International Journal of Service Science, Management, Engineering, and Technology, 3(3), 26-48.

Rabetino, R., Harmsen, W., Kohtamäki, M., \& Sihvonen, J. (2018). Structuring servitization-related research. International Journal of Operations and Production Management, 38(2), 350-371.

Raja, J.Z., Chakkol, M., Johnson, M., \& Beltagui, A. (2017). Organizing for servitization: examining front-and back-end design configurations, International Journal of Operations \& Production Management, 38(1), 249-271.

Rajala, R., Brax, S. A., Virtanen, A., \& Salonen, A. (2019). The next phase in servitization: transforming integrated solutions into modular solutions. International Journal of Operations and Production Management, 39(5), 630-657. 
Salvador, F., Forza, C., \& Rungtusanatham, M.J. (2002). Modularity, product variety, production volume, and component sourcing: theorizing beyond generic prescriptions, Journal of Operations Management, 20(5), 549-575.

Salvador, F. (2007). Toward a product system modularity construct: Literature review and reconceptualization. IEEE Transactions on Engineering Management, 54(2), 219-240.

Salonen, A., \& Jaakkola, E. (2015). Firm boundary decisions in solution business: Examining internal vs. external resource integration, Industrial Marketing Management, 51(November), 171-183.

Salonen, A., Rajala, R. \& Virtanen, A. (2018). Leveraging the benefits of modularity in the provision of integrated solutions: a strategic learning perspective, Industrial Marketing Management, 68, $13-24$.

Santos, F.M., \& Eisenhardt, K.M. (2005). Organizational boundaries and theories of organization, Organization Science, 16 (5), 491-508.

Santos, F.M., \& Eisenhardt, K.M. (2009). Constructing markets and shaping boundaries: Entrepreneurial power in nascent fields The Academy of Management Journal, 52 (4), 643-671.

Schilling, M. A. (2000). Toward a general modular systems theory and its application to interfirm product modularity. Academy of Management Review, 25: 312-334.

Silvestro, R., Fitzgerald, L., Johnston, R. \& Voss, C.A. (1992). Towards a classification of service processes, International Journal of Service Industry Management, 3(3), 62-75.

Silvestro, R. \& Lustrato, P. (2015). Exploring the 'mid office' concept as an enabler of mass customization in services, International Journal of Operations \& Production Management, 35(6), 866-894.

Simon, H. (1996). The Sciences of the Artificial, MIT Press.

Slater, M. (2006), The boundary of the firm, in Faulkner, D. O., \& Campbell, A. (Eds.). The Oxford handbook of strategy: a strategy overview and competitive strategy. Oxford University Press.

Smith, L., Ng, I.C.L., \& Maull. R. (2012). The Three Value Proposition Cycles of Equipment-based Service, Production Planning \& Control, 23 (Jul.), 553-570.

Smith, L., Maull, R., \& Ng, I. C. L. (2014). Servitization and operations management: A service dominant-logic approach. International Journal of Operations and Production Management, 34(2), 242-269.

Smith, W. K., \& Lewis, M. W. (2011). Toward a theory of paradox: a dynamic equilibrium model of organizing. Academy of Management Review, 36(2), 381-403.

Sousa, R., \& Voss., C. (2008). Contingency research in operations management practices, Journal of Operations Management, 26(6): 697-713.

Sousa, R., \& da Silveira, G. J. C. (2017). Capability antecedents and performance outcomes of servitization: Differences between basic and advanced services. International Journal of Operations and Production Management, 37(4), 444-467. 
Squire, B., S. Brown, J. Readman, \& J. Bessant. 2006. The impact of mass customisation on manufacturing trade-offs, Production and Operations Management, 15(1), 10-21.

Valtakoski, A. (2017). Explaining servitization failure and deservitization: A knowledge-based perspective, Industrial Marketing Management, 60 (2017), 138-150.

Verganti, R. (1997). Leveraging on systemic learning to manage the early phases of product innovation projects. $R$ and D Management, 27(4), 377-392.

Visnjic Kastalli, I., \& Van Looy, B. (2013). Servitization: Disentangling the impact of service business model innovation on manufacturing firm performance. Journal of Operations Management, 31(4), 169-180.

Voss, C., Tsikriktsis, N. \& Frohlich, M. (2002). Case research in operations management, International Journal of Operations \& Production Management, 22(2), 195-291.

Weinberg, G.M. (2001). An Introduction to General Systems Thinking - Silver Anniversary Edition. Dorset House, New York.

Yin, R. (2003). Case Study Research and Applications: Design and Methods. SAGE. 
Appendix A

\section{Interview Protocol}

Interviewee Questions for round 1 and 2 semi-structured interviews are as follows:

1) How would you describe the philosophy behind Urgent Operational Requirements?

2) What was the role of environmental [contextual] factors in the need for an Urgent Operational Requirement?

3) What do you consider when designing Urgent Operational Requirements?

4) What is the role and/or benefit of modularity in the design and provision of an Urgent Operational Requirement?

5) What role does modularity play in having the capability to adapt vehicles to different requirements?

6) What role could additive manufacturing play in supporting design and production of Urgent Operational Requirements? 


\begin{tabular}{|c|c|c|c|c|}
\hline Interviews & \multirow{2}{*}{$\begin{array}{c}\text { Date (month } \\
\text { and year) }\end{array}$} & \multirow{2}{*}{$\begin{array}{c}\text { Duration } \\
\begin{array}{c}\text { (minutes and } \\
\text { seconds) }\end{array} \\
\end{array}$} & \multicolumn{2}{|c|}{ Contributing data } \\
\hline & & & Round 1 & Round 2 \\
\hline Service Staff & May 2015 & 36.54 & $X$ & \\
\hline Service Staff & May 2015 & 32.55 & $X$ & \\
\hline Service Staff & May 2015 & 31.31 & $X$ & \\
\hline Service Staff & May 2015 & 35.51 & $X$ & \\
\hline Service Staff & May 2015 & 33.52 & $\mathrm{X}$ & \\
\hline Engineering Staff & May 2015 & 37.13 & $X$ & \\
\hline Engineering Staff & May 2015 & 40.11 & $\mathrm{X}$ & \\
\hline Engineering Staff & May 2015 & 46.02 & $X$ & \\
\hline Engineering Staff & May 2015 & 34.37 & $\mathrm{X}$ & \\
\hline Engineering Staff & May 2015 & 34.10 & $\mathrm{X}$ & \\
\hline Engineering Staff & May 2015 & 34.54 & $X$ & \\
\hline Engineering Staff & May 2015 & 37.26 & $\mathrm{X}$ & \\
\hline Engineering Staff & May 2015 & 39.01 & $\mathrm{X}$ & \\
\hline Engineering Staff & May 2015 & 34.12 & $\mathrm{X}$ & \\
\hline Engineering Staff & May 2015 & 35.55 & $\mathrm{X}$ & \\
\hline Engineering Staff & May 2015 & 34.11 & $\mathrm{X}$ & \\
\hline Engineering Staff & May 2015 & 38.03 & $X$ & \\
\hline Engineering Staff & May 2015 & 37.38 & $\mathrm{X}$ & \\
\hline Engineering Staff & May 2015 & 33.57 & $X$ & \\
\hline Engineering Staff & May 2015 & 56.52 & $\mathrm{X}$ & \\
\hline Engineering Staff & May 2015 & 50.43 & $X$ & \\
\hline Engineering Staff & May 2015 & 41.39 & $\mathrm{X}$ & \\
\hline Technology Lead & February 2016 & 58.00 & & $X$ \\
\hline Head of Availability Services & February 2016 & 50.29 & & $\mathrm{X}$ \\
\hline Technical Programme Manager & February 2016 & 68.14 & & $\mathrm{X}$ \\
\hline $\begin{array}{l}\text { Platform Manager for Vehicle } \\
\text { A }\end{array}$ & February 2016 & 51.34 & & $\mathrm{X}$ \\
\hline $\begin{array}{l}\text { Platform Manager for Vehicle } \\
\text { B }\end{array}$ & February 2016 & 53.27 & & $\mathrm{X}$ \\
\hline $\begin{array}{l}\text { Platform Manager for Vehicle } \\
\text { C }\end{array}$ & February 2016 & 50.56 & & $\mathrm{X}$ \\
\hline $\begin{array}{l}\text { Field Service Representative } \\
\text { Manager }\end{array}$ & February 2016 & 41.49 & & $X$ \\
\hline $\begin{array}{l}\text { Strategy Executive and } \\
\text { Principle Technologist }\end{array}$ & February 2016 & 54.31 & & $\mathrm{X}$ \\
\hline Total & & $\begin{array}{l}1260 \text { minutes } \\
47 \text { seconds }\end{array}$ & 22 & 8 \\
\hline Other material & Years & $N$ & & \\
\hline Observations (vehicles) & $2014-2015$ & $\begin{array}{l}3 \text { hours over } 18 \\
\text { months }\end{array}$ & & \\
\hline $\begin{array}{l}\text { Confidential company } \\
\text { documents }\end{array}$ & $2014-2018$ & 14 pages & & \\
\hline Publicly available documents & 2014-2018 & 430 pages & & \\
\hline $\begin{array}{l}\text { Meetings with participants } \\
\text { (recorded as field notes) }\end{array}$ & 2014-2018 & 8 meetings & & \\
\hline $\begin{array}{l}\text { Company PowerPoint } \\
\text { presentations on vehicle design } \\
\text { and modularity }\end{array}$ & 2014 & $\begin{array}{l}1 \text { meeting }(2 \\
\text { hours long) }\end{array}$ & $\mathrm{X}$ & \\
\hline
\end{tabular}


Table i. Overview of study data. 


\begin{tabular}{|c|c|}
\hline Steps & $\begin{array}{l}\text { Process description } \\
\end{array}$ \\
\hline Fieldwork preparation & $\begin{array}{l}\text { Review of the relevant literature } \\
\text { Initial meeting with project champions to } \\
\text { familiarise ourselves with the case organisation } \\
\text { and discuss data collection } \\
\text { Creation of an interview protocol based on the } \\
\text { literature }\end{array}$ \\
\hline Familiarising ourselves with the data & $\begin{array}{l}\text { Interviews transcribed verbatim by a third-party } \\
\text { transcription service } \\
\text { Transcripts are read by the lead researcher to } \\
\text { ensure accuracy of the transcripts } \\
\text { Transcripts re-read several times to familiarise } \\
\text { the researcher with the data } \\
\text { Notes made on the transcript to capture initial } \\
\text { thoughts. }\end{array}$ \\
\hline Generating initial codes & $\begin{array}{l}\text { Relevant data across the entire dataset were } \\
\text { allocated codes } \\
\text { First presentation to project champions of the } \\
\text { project to receive their feedback }\end{array}$ \\
\hline Searching for themes and sub themes & $\begin{array}{l}\text { Data allocated to initial codes were re-read and } \\
\text { allocated to potential themes and sub themes to } \\
\text { display relationships } \\
\text { All data relevant for each theme and sub theme } \\
\text { were gathered together } \\
\text { First-order categories (initial codes) were } \\
\text { collapsed into sub themes } \\
\text { Sub themes were aggregated into central themes } \\
\text { Data was combined and contrasted with the } \\
\text { extant literature (e.g., modularity, servitization, } \\
\text { paradox) } \\
\text { Initial themes and sub-themes were compiled }\end{array}$ \\
\hline Reviewing the themes and sub themes & $\begin{array}{l}\text { Themes and sub themes were reviewed } \\
\text { Themes, sub themes and first-order categories } \\
\text { were discussed with wider research team to } \\
\text { reach agreement }\end{array}$ \\
\hline Defining and naming themes and sub-themes & $\begin{array}{l}\text { Coded data were re-read and checked, helping } \\
\text { to refine themes and sub-themes and the overall } \\
\text { story told by the analysis } \\
\text { Clear definitions and names for each theme and } \\
\text { sub theme were derived } \\
\text { Second presentation to project champions to } \\
\text { receive feedback }\end{array}$ \\
\hline Production of the output & $\begin{array}{l}\text { Analysis was written up in a manner that } \\
\text { allowed for meaningful representations of the } \\
\text { analysis to be presented } \\
\text { Final workshop with the project champions and } \\
\text { dissemination of final report for review and } \\
\text { feedback } \\
\text { Final checks and refinements to the analysis } \\
\text { applied following feedback }\end{array}$ \\
\hline
\end{tabular}

Table ii. Process of thematic analysis (adapted from Braun \& Clark, 2006). 


\begin{tabular}{|c|c|c|c|}
\hline $\begin{array}{c}\text { Area of } \\
\text { Capability } \\
\text { Change }\end{array}$ & $\begin{array}{c}\text { Original } \\
\text { Design }\end{array}$ & UORs & $\begin{array}{l}\text { Architectural } \\
\text { Change }\end{array}$ \\
\hline Mobility & $\mathrm{X}$ & & $X$ \\
\hline Mobility & $\mathrm{X}$ & & $\mathrm{X}$ \\
\hline Mobility & $\mathrm{X}$ & & $\mathrm{X}$ \\
\hline Mobility & 0 & & 0 \\
\hline Mobility & 0 & & 0 \\
\hline Mobility & $\bar{X}$ & & \\
\hline Environmental & & $\mathrm{X}$ & $\mathrm{X}$ \\
\hline Environmental & & $\mathrm{X}$ & $\mathrm{X}$ \\
\hline Environmental & & $\mathrm{X}$ & $\mathrm{X}$ \\
\hline Environmental & & $\mathrm{X}$ & $\mathrm{X}$ \\
\hline Environmental & & $\mathrm{X}$ & $\mathrm{X}$ \\
\hline Environmental & & $\bar{X}$ & $\bar{X}$ \\
\hline Environmental & & $\mathrm{X}$ & $\mathrm{X}$ \\
\hline Environmental & & $X$ & $\mathrm{X}$ \\
\hline Protection & & $X$ & $\mathrm{X}$ \\
\hline Protection & & $X$ & \\
\hline Protection & & $X$ & $\mathrm{X}$ \\
\hline Environmental & & $\mathrm{X}$ & $\mathrm{X}$ \\
\hline Environmental & & $\mathrm{X}$ & $\mathrm{X}$ \\
\hline Mobility & & $\mathrm{X}$ & $\mathrm{X}$ \\
\hline Mobility & & $\mathrm{X}$ & $\mathrm{X}$ \\
\hline Mobility & & $X$ & $\mathrm{X}$ \\
\hline Environmental & & $\mathrm{X}$ & 0 \\
\hline Protection & & $\mathrm{X}$ & $\mathrm{X}$ \\
\hline Cost reduction & & & $\mathrm{X}$ \\
\hline Environmental & & & $\mathrm{X}$ \\
\hline Cost reduction & & & $\mathrm{X}$ \\
\hline Protection & & & $\mathrm{X}$ \\
\hline Lethality & & & 0 \\
\hline Mobility & & & 0 \\
\hline Mobility & & & 0 \\
\hline Mobility & & & 0 \\
\hline Protection & & & $\mathrm{X}$ \\
\hline Environmental & & $\mathrm{X}$ & $\mathrm{X}$ \\
\hline Protection & & $X$ & 0 \\
\hline Lethality & & $\mathrm{X}$ & $\overline{0}$ \\
\hline Environmental & & $\mathrm{X}$ & 0 \\
\hline Lethality & & $\mathrm{X}$ & 0 \\
\hline Environmental & & $\mathrm{X}$ & 0 \\
\hline
\end{tabular}

Table iii. Pre, during and post architectural change 